\title{
O COTIDIANO DAS RELAÇÕES FAMILIARES COM INDIVÍDUO DEPENDENTE QUÍMICO
}

Keity Laís Siepmann Soccol ${ }^{1}$, Marlene Gomes Terra², Danilo Bertasso Ribeiro ${ }^{3}$, Joze Karlem da Silva Teixeira4, Daiana Foggiato de Siqueira' ${ }^{1}$, Sadja Cristina Tassinari de Souza Mostardeiro ${ }^{2}$

RESUMO: Objetivou-se conhecer o cotidiano das relações familiares com um indivíduo dependente químico. Trata-se de um estudo descritivo e com abordagem qualitativa, constituído de uma releitura em banco de dados de pesquisa sobre $\mathrm{O}$ cuidado familial ao indivíduo dependente de álcool e outras drogas. Os dados foram coletados de agosto a setembro de 2011 por meio de entrevista aberta e gravada a 11 familiares. As entrevistas foram submetidas à Análise de Conteúdo Temática e resultaram nas categorias Dificuldades no convívio familiar e Desequilibrio na relação familiar. Evidencia-se que a dependência química ocasiona estreitamento dos laços de confiança nas relações intrafamiliares e pode causar o adoecimento das famílias. Concluiuse que a dependência química contribui para a deteriorização das relações familiares na qual, tanto o dependente químico, como a sua família tornam-se escravos das drogas, sofrem preconceito e exclusão social, sendo estigmatizados pela sociedade. DESCRITORES: Enfermagem; Transtornos relacionados ao uso de substâncias; Família; Relações familiares.

\section{EL COTIDIANO DE LAS RELACIONES FAMILIARES CON INDIVIDUO DEPENDIENTE QUÍMICO}

RESUMEN: Fue objetivo de este estudio conocer el cotidiano de las relaciones familiares con un individuo dependiente químico. Es un estudio descriptivo de abordaje cualitativo, constituido de una relectura en banco de datos de investigación sobre El cuidado familiar al individuo dependiente de alcohol y otras drogas. Los datos fueron obtenidos de agosto a septiembre de 2011 por medio de entrevista abierta y grabada con 11 familiares. Las entrevistas fueron sometidas al Análisis de Contenido Temático y resultaron en las categorías Dificultades para convivir en familia y Desequilibrio en la relación familiar. Se muestra evidente que la dependencia química ocasiona perjuicios en la confianza de las relaciones intrafamiliares y puede adolecer las familias. Se concluye que la dependencia química contribuye para el deterioro de las relaciones familiares en la cual, tanto el adicto, como su familia se vuelven esclavos de las drogas, sufren prejuicio y exclusión social, siendo estigmatizados por la sociedad.

DESCRIPTORES: Enfermería; Trastornos relacionados al uso de substancias; Familia; Relaciones familiares.

\section{THE ROUTINE OF FAMILY RELATIONSHIPS WITH A SUBSTANCE DEPENDENT INDIVIDUAL}

ABSTRACT: The aim was to investigate the routine of family relationships with a substance dependent individual. It is a descriptive study with a qualitative approach constituted by a rereading of a research database on 'The family care for the individual who is dependent on alcohol and other drugs'. The data were collected in August - September 2011 through open, recorded, interviews with 11 family members. The interviews were subjected to Thematic Content Analysis, resulting in the categories Difficulties in family coexistence and Imbalance in the family relationship. It is evidenced that substance dependence weakens the bonds of trust in intrafamily relationships and can cause family members to fall ill. It is concluded that substance dependence contributes to deterioration of family relationships, in which both the substance abuser and his family become slaves of the drug, and suffer prejudice and social exclusion, being stigmatized by society. DESCRIPTORS: Nursing; Disturbances related to substance use; Family; Family relationships.

\footnotetext{
${ }^{1}$ Enfermeira. Mestranda em Enfermagem. Universidade Federal de Santa Maria. Santa Maria-RS-Brasil

${ }^{2}$ Enfermeira. Doutora em Enfermagem. Professora da Universidade Federal de Santa Maria. Santa Maria-RS-Brasil

${ }^{3}$ Enfermeiro. Mestre em Enfermagem. Doutorando em Enfermagem. Universidade Federal de Santa Maria. Santa Maria-RS-Brasil

${ }^{4}$ Acadêmica de Enfermagem. Universidade Federal de Santa Maria. Santa Maria-RS-Brasil
}

Autor correspondente:

Keity Laís Siepmann Soccol

Universidade Federal de Santa Maria

Av. Roraima, 1000 - 97105-900 - Santa Maria-RS-Brasil

E-mail: keitylais@hotmail.com
Recebido: 25/05/2013

Aprovado: 03/02/2014

Cogitare Enferm. 2014 Jan/Mar; 19(1):116-22 


\section{INTRODUÇÃO}

As drogas são utilizadas pelo ser humano desde o início da história da humanidade como um meio de socialização. No decorrer do tempo, elas também passaram a ser consumidas para o enfrentamento de problemas e por questões culturais ou religiosas, dentre outros motivos. Entretanto, a relação entre o uso de drogas e os problemas sociais é recente ${ }^{(1)}$.

Atualmente, o abuso de drogas é considerado um problema de saúde pública, pois ocasiona danos de diferentes maneiras ao sujeito, à família e à sociedade. Esses danos podem ser observados por meio de situações, como a repetência na escola, a perda do emprego, a violência, rupturas familiares, crimes, acidentes, entre ou$\operatorname{tros}^{(2)}$. Ainda, o ser humano relaciona-se de maneira diferente com cada tipo de droga e, dependendo do contexto, essa pode ser inofensiva ou apresentar riscos. Contudo, também, pode assumir padrões de uso disfuncionais, levando a prejuízos biológicos, psicológicos e sociais ${ }^{(3)}$.

Nessa perspectiva, quando o usuário de drogas chega a um padrão de consumo descontrolado desenvolve o que se conhece por dependência química, condição em que o usuário necessita de repetidas doses da droga para sentir-se bem ou para evitar sensações desagradáveis. Isso significa que o usuário já não possui controle sobre o uso de drogas, mesmo quando há prejuízos à sua saúde e aos seus relacionamentos sociais ${ }^{(4)}$. Acredita-se que a dependência química é resultado de inadaptação do indivíduo à realidade, bem como da dificuldade em lidar com o meio social, ou ainda, da incapacidade do mesmo em resolver problemas que a vida lhe apresenta.

Desse modo, uma das principais consequências do uso de drogas revela-se pela instabilidade no comportamento do usuário, podendo ocasionar desequilíbrio no cotidiano das pessoas que integram o grupo fami$\operatorname{liar}^{(5)}$. É preciso considerar que a família constitui um ambiente de cuidado em que são realizadas trocas entre si e compartilhamento de ideias e apoio ${ }^{(6)}$. Quando as pessoas se sentem bem por serem reconhecidas e aceitas com suas particularidades e singularidades, elas conseguem se expressar de forma autêntica e se responsabilizam umas pelas outras ${ }^{(6)}$.

Nos últimos anos, alguns pesquisadores têm investigado o cotidiano das famílias que possuem indivíduos com transtornos mentais ${ }^{(7-8)}$ e outras doenças crônicas $^{(9-10)}$. No entanto, há uma lacuna no conhecimento acerca das famílias que possuem indivíduos com dependência química. Cabe lembrar que a maioria dos estudos sobre dependência química trazem, como principais sujeitos, populações específicas, tais quais adolescentes e estudantes usuários de drogas ${ }^{(11-13)}$. Eles mostram também que a família vem sendo referenciada apenas enquanto seu papel de protetora ou como tendo influência para a inserção desses sujeitos no consumo de drogas ${ }^{(11-13)}$. No entanto, não abordam especificamente as necessidades e a dinâmica dessas famílias.

Com relação ao cotidiano de famílias que convivem com indivíduos dependentes químicos, percebeu-se que há escassez de publicações, justificando a relevância desse estudo. Isso vai ao encontro de que, mesmo diante do quantitativo alarmante de dependentes químicos e das consequências da dependência à família, essa temática ainda é pouco estudada por profissionais e estes também não estão devidamente preparados para atender aos familiares de dependentes químicos ${ }^{(14-15)}$. Assim, é necessário o desenvolvimento de mais estudos sobre a temática no que tange as relações familiares com indivíduos dependentes químicos a fim de contribuir com a produção científica e de fornecer subsídios aos profissionais da área da saúde.

Diante das repercussões do impacto da dependência química nas relações familiares, questiona-se: como é o cotidiano das relações familiares com um indivíduo dependente químico? Para atender a essas questões, o objetivo desse estudo foi descrever o cotidiano das relações familiares que possui um indivíduo dependente químico.

\section{MÉTODO}

Trata-se de um estudo de natureza descritiva e com abordagem qualitativa, constituído de uma releitura em banco de dados da pesquisa $\mathrm{O}$ cuidado familial ao indivíduo dependente de álcool e outras drogas, cujo protocolo do projeto de pesquisa foi aprovado pelo Comitê de Ética em Pesquisa sob Parecer n. 0159.0.243.000-11, seguindo-se os princípios e diretrizes de ética em pesquisa.

A pesquisa foi realizada em um Centro de Atenção Psicossocial álcool e drogas (CAPSad) de um município do Estado do Rio Grande do Sul. Foram entrevistados 11 familiares de indivíduos dependentes químicos, tendo como critérios de inclusão: ser familiar que frequenta o grupo de familiares do CAPSad; ser familiar com parentesco de primeiro e segundo grau; ser cônjuge de indivíduo dependente químico; considerar apenas um familiar por indivíduo dependente químico. Como critério de exclusão, consideraram-se os familiares de dependentes químicos com idade inferior a 18 anos. 
A produção de dados ocorreu no período de agosto a setembro de 2011 por meio de entrevista aberta e gravada. Essa foi realizada em uma sala disponibilizada pelo CAPSad a fim de garantir a privacidade dos familiares. Na entrevista, foi proposta a seguinte questão: Como é, para você, cuidar do (nome do indivíduo dependente de álcool e outras drogas)? Para preservar o sigilo da identidade dos familiares, foi utilizada a letra ' $F$ ' seguida de um número que corresponde à ordem sucessiva das entrevistas (F1, F2, F3,...).

Após a produção de dados, as entrevistas foram transcritas na íntegra pelos pesquisadores e submetidas à Análise de Conteúdo Temática, dividida em três fases: pré-análise, exploração do material e tratamento dos resultados obtidos ${ }^{(16)}$.

$\mathrm{Na}$ fase de pré-análise, realizou-se uma leitura flutuante das entrevistas para se obter familiaridade com o conteúdo. Após, buscou-se os núcleos de sentido, agrupou-se as ideias afins (valores, crenças e concepções dos familiares) e as identificações de argumentos presentes nos depoimentos, dos quais se extraiu um recorte das respostas dos familiares quanto à questão central. Na sequência, foi realizada a codificação cromática dos achados e a categorização dos conceitos que conduziram à análise. Foram constituídos questionamentos teóricos por meio de várias leituras, buscando-se identificar a relevância do conteúdo. No que tange à fase de exploração do material, foram identificadas as ideias convergentes pela leitura $\mathrm{e}$ releitura de cada entrevista, buscando-se reafirmá-las ao longo dos depoimentos dos familiares. Finalmente, por meio das leituras dos depoimentos, buscou-se identificar as categorias entre si, o que permitiu aproximar os aspectos que se inter-relacionavam e identificar as unidades de registro por meio de recortes direcionados pelos temas, localizando-se os núcleos de significados.

\section{RESULTADOS}

Da análise dos achados, emergiram duas categorias: dificuldades no convívio familiar e desequilíbrio na relação familiar.

\section{Dificuldades no convívio familiar}

Essa categoria evidenciou que a convivência dos familiares com um indivíduo dependente químico interfere no cotidiano das relações familiares:

Em casa dá nojo. Já tomou café? Já tomou remédio? Tu quer almoço? Tudo assim, por causa da bebida. (F7)
Tem que ir na esquina, tem que ir junto. É horrivel, é muito difícil. (F8)

Tem que ter paciência, tem que tá ajeitando ele, tentando acomodar, às vezes ele fica numa carência [...]. Ele parece uma criança pequena [...]. Ele é dependente de mim. (F10)

Conviver cotidianamente com um indivíduo dependente químico requer uma reorganização da família, pois a mesma necessita dedicar mais tempo e atenção a esse uma vez que o mesmo passa a ser dependente de seus cuidados. Esses vão, desde o cuidado do dia-a-dia, até o cuidado à saúde. Nesse mesmo contexto, a família vivencia, no seu cotidiano, o retrocesso do dependente químico com relação às suas responsabilidades, deixando de ter credibilidade na visão da mesma. Isso ocasiona o estreitamento dos laços de confiança na relação intra-familiar:

Não tem como eu confiar, deixar meus filhos com ele [...]. Ele vai no bar tomar bebida. Ele quer levar a pequena [filha] pra passear [...]. Então, quando ele fica com ela, eu fico em pânico, tenho que recomendar um vizinho: olha, tu repara. (F10)

Os anseios expressados pelo familiar ocorrem devido ao comportamento instável do dependente químico, o que causa exaustão em seu convívio com o mesmo e acarreta sentimentos de insegurança e de impotência. Dessa forma, identifica-se que a família não está preparada para suportar tal grau de desorganização provocado pelas condições de incerteza. Nesse sentido, mesmo que só um membro da família seja dependente químico, todos precisam de tratamento, pois a família adoece junto.

Dentre as alterações de comportamento que modificam o cotidiano da família, destaca-se a agressividade, por parte do indivíduo dependente químico, que prejudica ainda mais as relações familiares. Dessa forma, a família vivencia diversas formas de sofrimento que desordenam sua vida, o que leva a consequências psicológicas e físicas, como se percebe nas falas a seguir.

Tudo era motivo para agredir, ia levando as coisas de dentro de casa, ia saindo com as coisas. A gente queria atacar, ele saía e grudava o que tivesse pela frente, dava empurrão, soco, qualquer coisa. (F4)

Chegava perto dele, ele empurrava [...]. Ele era bem 
violento, já chegava na porta quebrando tudo, querendo me bater [...]. Tinha que me esconder dele em roda da casa ou na casa do vizinho para ele não me achar, ele era cruel. (F6)

As implicações da dependência química influenciam diretamente no âmbito familiar, transformando as relações tranquilas em agressivas e desarmônicas. Com isso, surgem os conflitos, as desavenças e o enfraquecimento dos vínculos, fazendo com que o familiar não se sinta mais tranquilo no seu próprio espaço.

Ultimamente, ele andava me ameaçando. Uma noite eu me acordei com ele dentro do meu quarto, já com a mão na minha garganta. (F1)

Percebe-se que a família, em seu cotidiano, sente-se intimidada e passa a conviver com as ameaças advindas do indivíduo dependente químico, dificultando ainda mais a convivência familiar.

\section{Desequilíbrio na relação familiar}

Nesta categoria, identificou-se que as relações dos indivíduos dependentes químicos com a família podem levar a uma desestruturação do seio familiar, ocasionando dificuldades de relacionamento entre os seus membros.

O pai dele não aceitava, se incomodava muito com aquilo e ele dizia que tinha muita vergonha do filho ser assim, porque ele dizia: eu sou militar, uma autoridade e como é que eu vou ter autoridade com os outros, se dentro de casa não tenho com meu filho! (F1)

Nós não deixava ele entra pra dentro de casa. Tinha o quarto dele lá nos fundo, e tem até hoje. Tem que me respeitar. E querer abusar aqui, esse bagulho aqui dentro de casa, não. Dentro do pátio, não. (F2)

Ele com o pai não se acerta, não aguenta ele [...]. Meu marido não aceitava essas coisas. Era muito brabo [...]. (F3)

O cotidiano das relações familiares pode, por vezes, causar sentimentos de vergonha na família e fazer com que ela se sinta desrespeitada quando há um dependente químico entre seus membros. Ainda, salienta-se que, quando a família não consegue mais suportar o difícil convívio, por ser conflituoso e desgastante física e emocionalmente, por vezes, abandona o familiar:

Ele, a princípio, se dava bem com os irmãos e tudo. Depois ele começou a incomodar. Ele ia lá num irmão e incomodava e aí, o irmão não quis ele mais: Não bota os pés aqui, porque eu não quero saber de ti [...]. (F1)

Disse para ele: o problema é teu! Eu não tenho mais nada a ver contigo [...]. Já fiz o que podia. (F2)

Digo então: tu vai procurar ajuda com as tuas pernas porque eu não vou te ajudar mais! E se tu voltar pra casa eu vou chamar a polícia, porque dentro de casa tu não entra mais. (F4)

A família dele, eles não ligam, e tem telefone! (F10)

Percebe-se, a partir dos depoimentos, que a presença do dependente químico no âmbito familiar causa sentimentos de revolta no cotidiano da família, fragilização e, até mesmo, rompimento dos laços familiares.

\section{DISCUSSÃO}

A dependência química se expressa por meio de condutas em que o indivíduo infringe regras e descumpre combinações com suas responsabilidades e compromissos, o que afeta as suas relações interpessoais. A família é uma instituição humana em que os indivíduos interagem por meio das relações emocionais e da história da qual fazem parte e compartilham entre si. O papel da família no desenvolvimento de seus membros é fundamental, pois os valores morais e sociais são transmitidos no seio familiar. É importante que a família que possui um membro com dependência química receba assistência de profissionais qualificados e sensíveis, capacitados para prepará-la ao enfrentamento da situação visto que a família representa a principal rede de apoio desse indivíduo.

A família sofre com as consequências da dependência química que produz conflitos e crises. Esses causam dificuldades no manejo da problemática entre os $\operatorname{membros}^{(14)}$. Ter um familiar dependente químico traz, para a família, experiências que transformam as relações estabelecidas entre ela e a sociedade, assim como a destruição de pessoas. Além disso, observam-se mudanças comportamentais, como a violência, a indiferença, o isolamento e o desprezo ${ }^{(17)}$.

O cotidiano com um indivíduo dependente químico repercute na dinâmica de toda a família, o que gera 
fragilidade nos vínculos afetivos e dificuldades nas relações familiares, exigindo esforço da família para conseguir manter as suas atividades diárias ${ }^{(5)}$. Logo, pode-se afirmar que a dependência química causa conflitos nas relações familiares, fazendo com que a família vivencie, no seu cotidiano, sentimentos de insegurança e incertezas frente à dependência química e passe a conviver com crises e desordens. Desse modo, ela necessita de uma intensa e constante reorganização.

O uso de drogas é compreendido, pela sociedade, como falta de caráter e, tanto o usuário como a sua família são estigmatizados e sofrem preconceito devido a essa situação, o que evidencia a necessidade de conhecer as famílias em seus diversos aspectos. Assim, cabe aos profissionais de saúde apoiar, auxiliar e fornecer suporte à família para que essa possa compreender e enfrentar o cotidiano que envolve o cuidar do usuário de drogas.

A família também precisa ter um acompanhamento terapêutico para aprender a lidar com as situações impostas pelo familiar dependente químico, pois essa sofre uma sobrecarga para cuidar de seu familiar dependente químico, passando por diversas dificuldades ${ }^{(18-19)}$. Seus integrantes são constantemente submetidos a desgastes físicos e emocionais que, em curto espaço de tempo, os tornam doentes em potencial ${ }^{(20)}$.

Nesse contexto, o enfermeiro pode ser considerado um agente mobilizador de forças, pois é um profissional que mantêm uma relação sistemática com as famílias, habilitando-as a identificar e desvelar as potencialidades familiares ${ }^{(21)}$. Para tanto, é necessário que esse profissional possa divulgar o trabalho de assistência extra-hospitalar, diminuir o preconceito, realizar atividades com fins educativos, atender às famílias e, assim, auxiliar para que o processo de reinserção social aconteça na prática e não somente na teoria ${ }^{(7)}$.

Evidencia-se a premência da efetividade das políticas de intervenções existentes focarem, tanto a prevenção e a promoção da saúde, quanto o processo de reabilitação multidimensional dos usuários como um todo, não esquecendo o contexto familiar que precisa ser amparado juntamente ao dependente de drogas ${ }^{(4)}$.

É imprescindível que políticas públicas e medidas preventivas do uso de drogas estejam relacionadas e englobem distintas esferas, dentre as quais: atenção básica, instituições de educação, família e sociedade. Assim, é essencial abordar essa temática na formação em Enfermagem, por meio das atividades de ensino e pesquisa, para que, dessa maneira, os alunos sejam instrumentalizados, enquanto futuros profissionais, para atuar com essa clientela ${ }^{(22)}$.

\section{CONSIDERAÇÕES FINAIS}

Os resultados desta pesquisa evidenciaram que a dependência química é um elemento de desintegração e deteriorização das relações familiares. O dependente químico e sua família tornam-se escravos das drogas, sofrem preconceito e exclusão social e são estigmatizados pela sociedade. Ademais, pode-se asseverar que há traços em comum no cotidiano desses familiares, o que inclui ameaças, violência física, dificuldades de relacionamento, sofrimento, angústias e transferência de responsabilidade. Percebe-se que as demandas pelo convívio com um dependente químico exigem constante enfrentamento das dificuldades relacionadas a essa convivência.

Identificou-se que as famílias de dependentes químicos tornam-se suscetíveis a uma diversidade de enfermidades, dentre elas, a co-dependência. Por isso, é imprescindível que sejam priorizadas ações de cunho preventivo ao uso de drogas antes mesmo de se ter um dependente químico no âmbito familiar.

O estudo alerta os profissionais da área da saúde para a necessidade de utilizar os espaços de educação em saúde para apoiar as famílias dos dependentes químicos a fim de resgatar os vínculos familiares fragilizados, bem como auxiliar no desenvolvimento de suas potencialidades e no enfrentamento do cotidiano. Recomenda-se o desenvolvimento de ações em prol da educação em saúde em espaços públicos, dentre os quais: as salas de espera das Unidades Básicas de Saúde e das Estratégias de Saúde da Família; os grupos de apoio a dependentes químicos e seus familiares no território em que residem; e os espaços para discussão e promoção da saúde em ambientes escolares.

Quanto à enfermagem, esse estudo forneceu subsídios para que se possa repensar a prática realizada junto aos familiares de dependentes químicos nesses espaços e ajudar essas famílias a partir de estratégias conjuntas com outros profissionais da área da saúde. No que tange a identificação desses familiares, ressalta-se que nem sempre os mesmos chegam ao serviço relatando sobre as dificuldades de se ter um dependente químico no lar. Portanto, cabe ao enfermeiro desenvolver sensibilidade e proporcionar momentos de escuta nesses serviços para que se possa, assim, compreender as necessidades dessas famílias.

Sugere-se que as questões de família de dependentes químicos sejam incorporadas, como conteúdos, na formação dos profissionais de saúde a fim de prepará-los para atender e intervir nessa realidade. Além disso, 
recomenda-se o incentivo de novas pesquisas sobre esta temática e a divulgação dos seus resultados em outras regiões do país, pois se trata de um tema relevante que permite à sociedade perceber o quanto a família é importante na prevenção e no tratamento da dependência química. Salienta-se a necessidade de serem realizados estudos que se aproximem do cotidiano da família e que sejam conduzidos a partir de uma abordagem que considera o ser humano em sua integralidade.

\section{REFERÊNCIAS}

1. Gabatz RIB, Johann M, Terra MG, Padoin SMM, Silva AA, Brum JL. Percepção do usuário sobre a droga em sua vida. Esc. Anna Nery. [Internet] 2013;17(3) [acesso em 15 nov 2013]. Disponível: http://dx.doi.org/10.1590/ S1414-81452013000300016

2. Schenker M. Valores familiares e uso abusivo de drogas. Rio de Janeiro: FIOCRUZ; 2008.

3. Duarte CE, Morihisa RS. Experimentação, uso, abuso e dependência de drogas. In: Secretaria Nacional de Políticas sobre Drogas. Prevenção do uso de álcool e outras drogas no ambiente de trabalho: conhecer para ajudar. 3a ed. Brasília: Ministério da Justiça; 2012.

4. Siqueira DF, Moreschi C, Backes DS, Lunardi VL, Filho WDL, Dalcin CB. Repercussões do uso de crack no cotidiano familiar. Cogitare enferm. [Internet] 2012;17(2) [acesso em 12 nov 2013]. Disponível: http:// ojs.c3sl.ufpr.br/ojs2/index.php/cogitare/article/view/235 $18 / 18465$

5. Soccol KLS. O cuidado familial ao indivíduo dependente de álcool e outras drogas. [trabalho de conclusão de curso]. Santa Maria (RS): Universidade Federal de Santa Maria; 2011.

6. Gutierrez DMD, Minayo MCS. Produção de conhecimento sobre cuidados da saúde no âmbito da família. Ciênc. saúde colet. [Internet] 2010;15(Suppl.1) [acesso em 12 nov 2013]. Disponível: http://dx.doi. org/10.1590/S1413-81232010000700062

7. Grandi AL de, Waidman MAP. Convivência e rotina da família atendida em CAPS. Cienc. cuid. saude. [Internet] 2011;10(4) [acesso em 8 ago 2013]. Disponível: http:// periodicos.uem.br/ojs/index.php/CiencCuidSaude/ article/viewFile/18321/pdf

8. Oliveira APP de, Caldana RHL. As Repercussões do Cuidado na Vida do Cuidador Familiar do Idoso com Demência de Alzheimer. Saúde Soc. São Paulo.
[Internet] 2012;21(3) [acesso em 8 ago 2013]. Disponível: http://dx.doi.org/10.1590/S0104-12902012000300013

9. Garcia RP, Budó MLD, Oliveira SG, Schimith MD, Wünsch S, Simon BS. Cotidiano e aprendizado de cuidadores familiares de doentes crônicos. Cienc. cuid. saude. [Internet] 2011;10(4) [acesso 9 ago 2013]. Disponível: http://periodicos.uem.br/ojs/index.php/ CiencCuidSaude/article/view/18312/pdf

10. Nóbrega VM, Reichert APS, Silva KL, Coutinho SED, Collet N. Imposições e conflitos no cotidiano das famílias de crianças com doença crônica. Esc. Anna Nery. [Internet] 2012;16(4) [acesso em 8 jul 2013]. Disponível: http://dx.doi.org/10.1590/S141481452012000400020

11. Dietz G, Santos CG, Hildebrandt LM, Leite MT. As relações interpessoais e o consumo de drogas por adolescentes. Rev. Eletrônica Saúde Mental Álcool Drog. [Internet] 2011;7(2) [acesso em 12 set 2013]. Disponível: http://pepsic.bvsalud.org/pdf/smad/ v7n2/06.pdf

12. Mosqueda-Díaz A,Ferriani MGC. Fatores protetores e de risco familiar, relacionados ao fenômeno de drogas, entre adolescentes tempranos de Valparaíso, Chile. Rev. Latino-Am. Enfermagem. [Internet] 2011;19(n. esp) [acesso em 13 out 2013]. Disponível: http://dx.doi. org/10.1590/S0104-11692011000700017

13. Garcia JJ, Pillon SC, Santos MA. Relações entre contexto familiar e uso de drogas em adolescentes de ensino médio. Rev. Latino-Am. Enfermagem. [Internet] 2011;19(n. esp) [acesso em 13 out 2013]. Disponível: http://dx.doi.org/10.1590/S0104-11692011000700013

14. Capistrano FC, Ferreira ACZ, Maftum MA, Kalinke LP, Mantovani MF. Impacto social do uso abusivo de drogas por dependentes químicos registrados em prontuários. Cogitare enferm. [Internet] 2013;18(3) [acesso em 16 nov 2013]. Disponível: http://ojs.c3sl.ufpr.br/ ojs/index. php/cogitare/article/view/33556/21055

15. Horta RL, EssweingC, HortaCL. Percepção de profissionais de saúde de CAPS I quanto a demandas relativas ao consumo de crack. Ciênc. saúde colet. [Internet] 2013;18(4) [acesso em 8 nov 2013]. Disponível: http://dx.doi.org/10.1590/S1413-81232013000400023

16. Minayo MCS. O desafio do conhecimento: pesquisa qualitativa em saúde. 12a ed. São Paulo: Hucitec; 2010.

17. Brusamarello T, Sureki M, Borrile D, Roehrs H, Maftum MA. Consumo de drogas: concepções de familiares 
de estudantes em idade escolar. SMAD. [Internet] 2008;4(1) [acesso em 6 ago 2013]. Disponível: http:// www.revistas.usp.br/smad/article/view/38664/41511

18. Alvarez SQ, Gomes GC, Oliveira AMN, Xavier DM. Grupo de apoio/ suporte como estratégia de cuidado: importância para familiares de usuários de drogas. Rev. Gaúcha Enferm. [Internet] 2012;33(2) [acesso em 8 nov 2013]. Disponível: http://seer.ufrgs. br/index.php/RevistaGauchadeEnfermagem/article/ view/24646/19499

19. Soccol KLS, Terra MG, Girardon-Perlini NMO, Ribeiro DB, Silva CT, Camillo LA. O cuidado familial ao indivíduo dependente de álcool e outras drogas. Rev Rene. [Internet] 2013;14(3) [acesso em 14 nov 2013]. Disponível: http://www.revistarene.ufc.br/revista/ index.php/revista/article/view/1104/pdf

20. Santos ECV, Martin D. Cuidadoras de pacientes alcoolistas no município de Santos, SP, Brasil. Rev. bras. enferm. [Internet] 2009;62(2) [acesso em 14 nov 2013]. Disponível: http://dx.doi.org/10.1590/S003471672009000200004

21. Dias AB, Silva MRS. Processos familiares no contexto do transtorno mental: um estudo sobre as forças da família. Cienc cuid saude. [Internet] 2010;9(4) [acesso em 13 out 2013]. Disponível: http://periodicos. uem.br/ojs/index.php/CiencCuidSaude/article/view/ $12047 / 7199$

22. Gabatz RIB, Schmidt AL, Terra MG, Padoin SMM, Silva AA, Lacchini AJB. Percepção dos usuários de crack em relação ao uso e tratamento. Rev. Gaúcha Enferm. [Internet] 2013;34(1) [acesso em 8 nov 2013]. Disponível:http://dx.doi.org/10.1590/S198314472013000100018 